\title{
A Study of Continuance Intention of Tablet Computer-Assisted Learning for Vocational High School Students
}

\author{
York Min-Yu Sun, Rong Jou Yang, Hann-Jang Ho, Yun-Ju Weng, and Bo-Zhang Chen
}

\begin{abstract}
Mobile devices have become a trend of attractive learning devices for education. Advances in technology of electronic products add more possibilities of mobile learning. Currently, more and more people use the Tablet computers, which have also been suitable for mobile learning due to the merit of the screen rendering, user-friendly interface, and system performance. In this study, a vocational high school was considered as an example in employing HTC Flyer Tablet computer, its software and digital teaching platform. We investigated the user behavior of first year students of all disciplines in the vocational high school after the Tablet computers-assisted teaching activities was implemented. We adopted questionnaire survey in which the questionnaire items were classified into four facets of performance expectation, effort expectation, social impact and facilitating conditions based on the Technology Acceptance Model (TAM) - Unified Theory of Acceptance and Use of Technology (UTAUT). The research results indicated that the facet of intention of use of Tablet computer was proportionally affected by the other three facets of effort expectation, social impact and facilitating conditions, which can be referenced by future Tablet computer-assisted teaching tool integrated with and employed in teaching activities and implementation.
\end{abstract}

Index Terms-Tablet computers, unified theory of acceptance and use of technology, teaching aids, e-learning.

\section{RESEARCH BACKGROUND}

Employing e-learning to assist traditional in-class learning has been the trend of modern education. But very often the implementation of e-learning was limited to the insufficiency of hardware facilities and design of learning activities, which resulted in decrease of learning motive of student and flexibility of implementation. This research provided each freshman and teacher in a vocational high school with a HTC Flyer Tablet computer and the installed e-learning software and platform, which was supported by the e-learning

Manuscript received October 29, 2016; revised January 12, 2017.

York Min-Yu Sun and Hann-Jang Ho is with the Department of Applied Digital Media, Wu Feng University, Min-Hsiung, Chiayi County, 625, Taiwan (e-mail: york@wfu.edu.tw,hhj@wfu.edu.tw).

Rong Jou Yang was with Wu Feng University, Min-Hsiung, Chiayi County, 625, Taiwan. He is now with the Department of Computer Science, the University of Texas at El Paso, El Paso, TX 79968 USA (e-mail: ryang@miners.utep.edu).

Yun-Ju Weng was with Wu Feng University, Min-Hsiung, Chiayi County, 625, Taiwan. She is now with the Private Dong Wu Senior Industrial Home Economics Vocational High School, Chiayi, 600, Taiwan (e-mail: saymay@dwvs.cy.edu.tw).

Bo-Zhang Chen is with the Department of Applied Digital Media, Wu Feng University, Min-Hsiung, Chiayi County, 625, Taiwan (e-mail: bai550799@gmail.com). platform initiative from LearnMode and used to conduct a teaching activities, exercise the learning activities, e-book reading, sharing of topic discussion, etc., in order for student to attain useful teaching information from the platform and have opportunities to express opinion, share though, and discuss interactively through the real-time mechanism of feedback.

We thought it's worth to study the effect of collaborative learning in which traditional in-class learning was assisted with the tool of Tablet computer. In this research, we conducted a teaching activity which was implemented in a vocational high school for freshman to investigate the students' interest in knowledge exploration, in-class participation, after-class information collection, and the effect of learning activities by employing Tablet computer-assisted teaching under the same learning conditions of time spent in a course and facilities so as to understand students' continuance intention of use after one year of experience of Tablet computer-assisted learning. In this research, we investigated users' intention of use and effect of Tablet computer-assisted teaching activities by employing Unified Theory of Acceptance and Use of Technology (UTAUT) by Venkatesh et al. as our research architecture [2]. The investigated issues were as follows:

1) Understood the users' acceptance of Tablet computer-assisted teaching activities.

2) Studied each significant correlation between four facets of performance expectation, effort expectation, social impact, and facilitating conditions and one facet of intention of use.

3) Investigated the difference of intention of use in the facets of performance expectation, effort expectation, social impact, and facilitating conditions affected by the factor of student' background.

\section{SURVEYS OF LITERATURES}

\section{A. IT Integrated Teaching and Tablet Computers Aid Learning}

In [3], Tseng indicated that IT integrated teaching can be customized to individual learning to promote learning effect.

In [4], Yang indicated that teachers would design more diverse teaching contents and students would also increase interest of learning by using Tablet computer in teaching or remedial teaching, which increased the interaction between users and promoted the teaching effect.

\section{B. Integrated Technology Acceptance Model}


In [5], Thompson et al. proposed Model of PC Utilization (MPCU) to predict computer use behavior of individuals based on Theory of Human Behavior in the field of social phycology.

In [6], Davis, Bagozzi, and Warshaw advocated that intention of use of innovative IT would be affected by interior and exterior motives.

In [7] [8], Ajzen investigated Theory of Planned Behavior (TPB) and advocated that the creation of individual behavior was derived from behavioral intention and which was mainly affected by attitudes of behavior, subjective regulation, and control of conscious behavior.

In [9], Davis Fred D. proposed the Technology Acceptance Model (TAM) to elucidate behavioral intention of users after employing innovative information technology.

In [2], Venkatesh integrated and summarized the related researches of TAM over the years and proposed Unified Theory of Acceptance and Use of Technology (UTAUT) as indicated in Fig.1, by which the ability of elucidation for use behavior can reach $70 \%$. Therefore, we developed research architecture based on UTAUT.

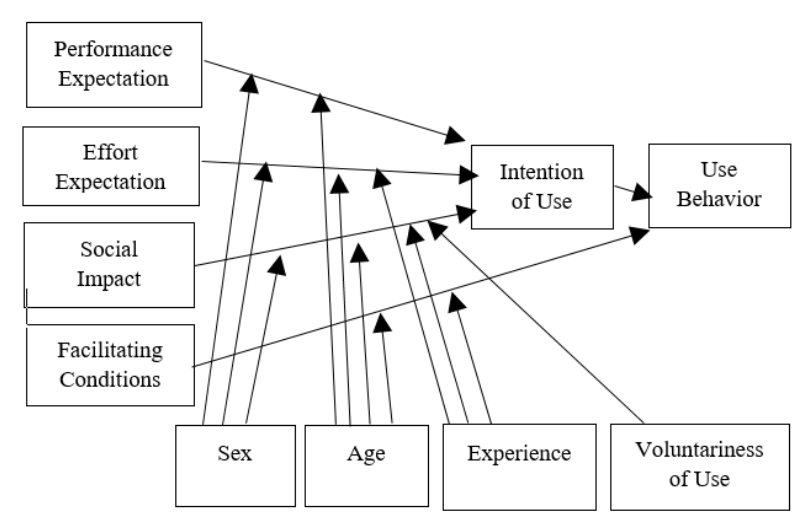

Fig. 1. Unified Theory of Acceptance and Use of Technology (UTAUT), Venkatesh (2003).

\section{RESEARCH METHODS}

\section{A. LearnMode e-Teaching Platform}

LearnMode in [1] provided the HTC Flyer Tablet computers for freshman and teachers of a number of high schools, which paired up the LearnMode e-learning platform to initiate a teaching experiment project oriented towards mobile e-learning. This e-learning platform provided not only the contents, tools, and a variety of Apps for learning, which was convenient for students to prepare, review, and self-practice a lesson, but also a design which was convenient for interaction between teachers/students and online communities for collaborative authoring or learning, through which to offer abundant learning contents and supporting partners.

In this study, we investigated the effect of Tablet computer-assisted teaching in a vocational high school by utilizing the LearnMode e-learning platform. The HTC Flyer Tablet computers dispatched to the freshman had been pre-installed of platform and groupware for courses learning of vocational high school. Main software systems consisted of three categories of learning mode: courses learning systems, interactive online community systems, and software tools. The courses learning systems included three learning software: Books, Course, and Practice.

The Books was composed of the e-textbooks (Textbook) of all textbooks in standard textbooks list of high school published by all publishers, teachers' self-authoring teaching materials, and group collaborative authoring systems. The Course collected the pre-recorded teaching videos of all high school courses, open courses from domestic and international famous universities, TED Talk selected videos, and travel English courses published by Let's Talk in English. The Practice provided tools for testing and gauging practices, which enabled students to conduct a self-testing practice including a test bank of 12000 questions.

The interactive online community systems provided common generalized functions of contents sharing, key notes sharing, bookmarks links sharing, dynamic messages, and Q\&A, in addition to the design of reward system for learning, which encouraged teachers and students to make an statement or a speech interactively, such as reading the articles and marking message in Textbook, watching videos in Course, answering questions from classmates, sharing articles or pictures, and conducting the tests in Practice in order to gain and accumulate the points and win a honor badge when the points were reached. The software tools included the self-practice software of high school mathematics released by the international well-known educational institution - Wolfram, well-known online English-Chinese dictionary, online real-time Chinese-English translation, and TuneIn Radio which aggregated fifty thousand stations in the world with selective language broadcasting, in addition to Internet browsers, calendars, maps, cameras, clock and memo book, and App download.

\section{B. Research Architecture and Hypothesis}

In this research, we investigated the effect of Tablet computers-assisted teaching and continuance intention on vocational high school students in four facets of performance expectation, effort expectation, social impact and facilitating conditions and three variables of sex, school system, and discipline based on UTAUT proposed by Venkatesh. The questionnaire was designed based on the four facets and three variables indicated in our research architecture and questionnaire data were collected and analyzed using statistical analysis software tools.

The TAM UTAUT proposed by Venkatesh consists of four variables of sex, age, experience and voluntariness of use. However, our research objects were the second year's students of vocational high school, who participated in LearnMode e-learning platform initiative, covered different school system and discipline, and had had one year experience of LearnMode-assisted learning. Besides, we investigated the effect of Tablet computer-assisted learning, which was big difference from technique-oriented facilitating conditions advocated in UTAUT. Therefore, three variables of age, experience, and voluntariness of use were deleted and school system and discipline were added to study the affection of sex, school system, and discipline on intention of use. Thus, UTAUT was modified to adjust the variables to fit in the situation of our research which architecture is indicated 
in Fig. 2.

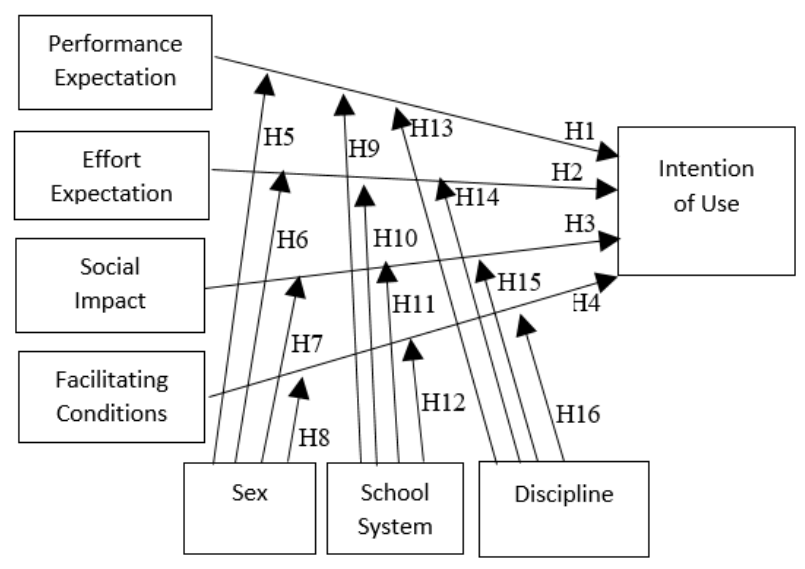

Fig. 2. Research architecture.

Based on the research results of UTAUT, we postulated that intention of use was positively and significantly affected by four facets of performance expectation, effort expectation, social impact, and facilitating conditions. But the intention of use of Tablet computer-assisted learning integrated with teaching and learning activities was also affected by the adjusted variables of sex, school system, and discipline.

\section{Questionnaire Design}

In this study, we adopted questionnaire survey in which the questionnaire was divided into two parts. The first part was profile data including sex, school system, and discipline measured by using Likert scale of five points replacing the recognition of strongly agree, agree, neutral, disagree, and strongly disagree with points $5,4,3,2$, and 1 respectively. The questionnaire also adopted positive questions answered by the testers. In order to increase the validity of contents, we invited five experts and scholars affiliated with universities and vocational high schools to evaluate and modify the questionnaire, then dispatch to vocational high school students who had one year experience of using LearnMode e-learning platform.

\section{RESEARCH ANALYSIS}

\section{A. Data Analysis of Questionnaire}

There were 695 questionnaires dispatched and 695 questionnaires was collected between September 11 and 30, 2015 , which was $100 \%$ of response rate. Male accounted for 308 which was $44.3 \%$ while female 387 was $55.7 \%$. The number of 1-3 hours of average Tablet computers use time accounted for 454 , which was $65.3 \%$, 4-6 hours 125 was $18.0 \%$, 0 hours 76 was $10.9 \%, 7-9$ hours 26 was $3.7 \%$, and greater than 10 hours 14 was $2.0 \%$. The school system and discipline of the sampled students is indicated in Table I.

\section{B. Analysis of Reliability and Validity}

- Bartlett's test

In this study, we employed Kaiser-Meyer-Olkin (KMO) measure and Bartlett's Test of Sphericity to test the data and the results were 0.952 of KMO (> 0.7) and 10793.372 of chi-square test of Bartlett's Test of Sphericity, which reached the level of significance and indicated that the factor analysis was fit to be further proceeded. Then, we conducted factor analysis to obtain five factors which interpretive variances were $24.5 \%, 23.0 \%, 16.6 \%, 15.7 \%$, and $15.6 \%$, total $94.5 \%$, by employing principle component analysis of summation of all facets by Wu [10]. Our study indicated a good construct validity based on the results after component analysis of the axis of rotation, which matched the five original classified facets of performance expectation, intention of use, effort expectation, facilitating conditions, and social impact.

Reliability analysis indicated that the reliability of questionnaire survey was highly consistent and stable in all facets of performance expectation, intention of use, effort expectation, facilitating conditions, and social impact and in entirety based on Cronbach's $\alpha$ coefficient which were 0.94, $0.94,0.93,0.95,0.96,0.98,0.92$ (> 0.07) respectively.

TABLE I: COLLECTED SAMPLING DATA ANALYSIS

\begin{tabular}{|c|c|c|c|c|}
\hline Variable & Category & Sample & $\%$ & Accumulated $\%$ \\
\hline \multirow{3}{*}{ Sex } & M & 308 & 44.3 & 44.3 \\
\hline & $\mathrm{F}$ & 387 & 55.7 & 100.0 \\
\hline & Total & 695 & 100 & 100.0 \\
\hline \multirow{3}{*}{$\begin{array}{l}\text { School } \\
\text { System }\end{array}$} & Normal & 330 & 47.5 & 47.5 \\
\hline & Technique & 212 & 30.5 & 78.0 \\
\hline & Collaboration & 153 & 22.0 & 100.0 \\
\hline \multirow{9}{*}{ Discipline } & $\begin{array}{l}\text { Restaurant } \\
\text { Management }\end{array}$ & 140 & 20.1 & 20.1 \\
\hline & Tourism Industry & 84 & 12.1 & 32.2 \\
\hline & Data Processing & 92 & 13.2 & 45.5 \\
\hline & Multimedia & 47 & 6.8 & 52.2 \\
\hline & Information & 86 & 12.4 & 64.6 \\
\hline & Auto Mechanics & 39 & 5.6 & 70.2 \\
\hline & $\begin{array}{l}\text { Early Childhood Care } \\
\& \text { Education }\end{array}$ & 48 & 6.9 & 77.1 \\
\hline & $\begin{array}{l}\text { Cosmetology \& } \\
\text { Fashion }\end{array}$ & 122 & 17.6 & 94.7 \\
\hline & Performing Art & 37 & 5.3 & 100.0 \\
\hline
\end{tabular}

\section{Statistical Analysis of Research Variables}

In this study, we adopted Likert scale of 5 points to measure the question items of questionnaire. After preliminary descriptive summary of the question items, the results indicated that all average of all question items was greater than 4 points. The average of four facets of performance expectation, effort expectation, social impact, and facilitating conditions, were $4.21,4.21,4.16$, and 4.17 respectively and the entirety of intention of use was 4.28 , which showed that the point of view from this research samplings were positive towards Tablet computer-assisted learning.

In order to understand the significant correlation between four facets of performance expectation, effort expectation, social impact, and facilitating conditions and the entirety of intention of use, we employed Pearson correlation analysis to test the correlation coefficient. The Pearson correlation coefficient of four facets of performance expectation, effort expectation, social impact, and facilitating conditions versus the facet of intention of use were $0.835,0.86,0.89,0.909$ 
respectively which all reached the level of significance $(p<$

II. 0.01 ) and were also highly proportional as indicated in Table

TABLE II: PEARSON CORRELATION ANALYSIS

\begin{tabular}{l|c|c|c|c}
\hline \multicolumn{1}{c|}{ Variable } & $\begin{array}{c}\text { Performance } \\
\text { Expectancy }\end{array}$ & Effort Expectance & Social Influence & Facilitating Conditions \\
\hline Performance Expectancy & 1.000 & 1.000 & & \\
Effort Expectance & $0.895^{* *}$ & $0.882^{* *}$ & 1.000 & \\
Social Influence & $0.873^{* *}$ & $0.873^{* *}$ & $0.906^{* *}$ & 1.000 \\
Facilitating Conditions & $0.849^{* *}$ & $0.860^{* *}$ & $0.890^{* *}$ & $0.909^{* *}$ \\
Intention of Use & $0.835^{* *}$ & & 1.000 \\
\hline
\end{tabular}

$* * p<.01$

\section{Regression Analysis}

In this study, we investigated the relationship and direction and degree of affection between independent and dependent variable by employing regression analysis. The affection of four independent variables on intention of use showed high ability of elucidation without considering adjusted variables as indicated in Table III. The regression variance of entirety was .856 which reached the level of significance $(p=0.000)$ and indicated that four independent variables could elucidate $85.6 \%$ variance of intention of use. We further tested the individual variables and the results indicated that facilitating conditions had the best ability of elucidation. Beta coefficient of facilitating conditions was highest $0.5(t=13.383, p<$ 0.001) which indicated that the higher the facilitating conditions, the higher the intention of use, social impact the second $0.270(t=6.736, p<0.001)$, effort expectation the third $0.145(t=3.810, p<0.001)$, which also reached the level of significance, and performance expectation the last $0.043(t=1.213, p=0.225)$ which didn't reach the level of significance. In summary, the results of regression analysis indicated that effort expectation, social impact, and facilitating conditions all possessed significant ability of forecast on intention of use.

\begin{tabular}{lccccc}
\multicolumn{5}{c}{ TABLE III: REGRESSION MODEL } \\
\hline & $\mathrm{B}$ & STD & Beta & $t$ & $p$ \\
\hline $\begin{array}{l}\text { Constant } \\
\text { Performance }\end{array}$ & 0.214 & 0.066 & & 3.233 & 0.001 \\
$\begin{array}{l}\text { Expectancy } \\
\text { Effort }\end{array}$ & 0.045 & 0.037 & 0.043 & 1.213 & 0.225 \\
$\begin{array}{l}\text { Expectance } \\
\text { Social Influence }\end{array}$ & 0.148 & 0.039 & 0.145 & 3.810 & 0.000 \\
$\begin{array}{l}\text { Facilitating } \\
\text { Conditions }\end{array}$ & 0.513 & 0.038 & 0.500 & 13.383 & 0.000 \\
\hline $\begin{array}{l}\text { Entirety } \\
\mathrm{R}^{2}=0.856\end{array}$ & \multicolumn{5}{c}{ Adj. $\mathrm{R}^{2}=0.856$} \\
\hline
\end{tabular}

In this study, we employed hierarchical regression analysis to investigate the affection of three adjusted variables of sex, school system, and discipline on four facets of performance expectation, effort expectation, social impact, and facilitating conditions and on intention of use and the results indicated that none of all the interactions between these three adjusted variables and four facets reached the level of significance, thus possessed no regulating effect as indicated in Table IV, $\mathrm{V}$, and VI.
TABLE IV: SEX CROSS ANALYSIS

\begin{tabular}{|c|c|c|c|c|c|}
\hline Variable & $\Delta \mathrm{R}^{2}$ & $\Delta \mathrm{F}$ & df1 & df2 & $\mathrm{p}$ \\
\hline $\begin{array}{c}\text { Performance } \\
\text { Expectance } \times \text { Sex }\end{array}$ & 0.001 & 1.963 & 1 & 685 & $\begin{array}{r}0.16 \\
2\end{array}$ \\
\hline $\begin{array}{l}\text { Effort Expectance } \\
\times \text { Sex }\end{array}$ & 0.001 & 3.114 & 1 & 685 & $\begin{array}{r}0.07 \\
8\end{array}$ \\
\hline Social Influence $\times$ Sex & 0.000 & 0.103 & 1 & 685 & $\begin{array}{r}0.74 \\
8\end{array}$ \\
\hline $\begin{array}{c}\text { Facilitating } \\
\text { Conditions } \times \text { Sex }\end{array}$ & 0.001 & 2.257 & 1 & 685 & $\begin{array}{r}0.13 \\
4 \\
\end{array}$ \\
\hline \multicolumn{6}{|c|}{ TABLE V: SCHOOL SYSTEM CROSS ANALYSIS } \\
\hline Variable & $\Delta \mathrm{R} 2$ & $\Delta \mathrm{F}$ & df1 & df 2 & $\mathrm{p}$ \\
\hline $\begin{array}{l}\text { Performance } \\
\text { Expectancy } \times \\
\text { School System }\end{array}$ & 0.000 & 0.168 & 2 & 683 & $\begin{array}{r}0.84 \\
5\end{array}$ \\
\hline $\begin{array}{l}\text { Effort Expectance } \\
\times \text { School System }\end{array}$ & 0.001 & 1.619 & 2 & 683 & $\begin{array}{r}0.19 \\
9\end{array}$ \\
\hline $\begin{array}{l}\text { Social Influence } \times \\
\text { School System }\end{array}$ & 0.001 & 0.114 & 2 & 683 & $\begin{array}{r}0.32 \\
9\end{array}$ \\
\hline $\begin{array}{l}\text { Facilitating } \\
\text { Conditions } \times \\
\text { School System }\end{array}$ & 0.001 & 2.755 & 2 & 683 & $\begin{array}{r}0.06 \\
4\end{array}$ \\
\hline
\end{tabular}

TABLE VI: DISCIPLINE CROSS ANALYSIS

\begin{tabular}{rrrrrr}
\hline Variable & \multicolumn{1}{c}{$\Delta \mathrm{R}$} & \multicolumn{1}{c}{$\Delta \mathrm{F}$} & df1 & df2 & Significance \\
\hline Performance Expectancy & 0.00 & 0.47 & 8 & 671 & 0.872 \\
$\times$ Discipline & 2 & 8 & & & \\
Effort Expectance $\times$ & 0.00 & 0.56 & 8 & 671 & 0.804 \\
Discipline & 2 & 9 & & & \\
Social Influence $\times$ & 0.00 & 1.17 & & & 0.315 \\
Discipline & 3 & 0 & 8 & 671 & \\
Facilitating Conditions $\times$ & 0.00 & 1.36 & & & 0.207 \\
Discipline & 3 & 8 & 8 & 671 & \\
\hline
\end{tabular}

TABLE VII: SUMMARY OF ESTABLISHED HYPOTHESIS BY HYPOTHESIS

\begin{tabular}{|c|c|c|}
\hline \multicolumn{3}{|c|}{ Testing } \\
\hline Hypothesis & Contents & $\mathrm{Y} / \mathrm{N}$ \\
\hline $\mathrm{H} 2$ & $\begin{array}{l}\text { Effort expectation was proportional to intention } \\
\text { of use with respect to Tablet computer-assisted } \\
\text { learning. }\end{array}$ & Y \\
\hline $\mathrm{H} 3$ & $\begin{array}{l}\text { Social impact was proportional to intention of } \\
\text { use. }\end{array}$ & $\mathrm{Y}$ \\
\hline $\mathrm{H} 4$ & $\begin{array}{l}\text { Facilitating conditions was proportional to } \\
\text { intention of use. }\end{array}$ & Y \\
\hline
\end{tabular}

In summary, the results of hypothesis $\mathrm{H} 2 、 \mathrm{H} 3 、 \mathrm{H} 4$ of hypothesis testing were established and summarized in Table 
VII.

\section{CONCLUSIONS AND SUGGESTIONS}

In this research, we investigated the key factors of teaching and learning activities assisted with Tablet computers based on UTAUT by Venkatesh et al.. We modified the variables in which two variables of experience and voluntariness were deleted and two variables of discipline and school system were added by considering general users of Tablet computer-assisted teaching and learning activities to study the affection of sex, discipline, and school system. Our research results through analysis of questionnaire survey were summarized as follows:

1) In whole, the users' acceptance of Tablet computer-assisted teaching and learning activities was high.

2) Effort expectation, social impact, and facilitating conditions were significantly proportional to intention of use of Tablet computer-assisted learning activities, especially the facilitating conditions and then the social impact.

3) The affection of three adjusted variables of sex, school system, and discipline on four facets of performance expectation, effort expectation, social impact, and facilitating conditions and on intention of use didn't reach the level of significance probably because of widespread use of mobile device of Tablet computers and cell phone. Thus, there was no significant difference.

This research was applied only to a sampled vocational high school in Chiayi County, but not other schools in other areas. Nowadays, intelligent cell phones have been very popular, which can be integrated with Tablet computer-assisted LearnMode system and implemented in other high schools of other areas to investigate the learning effect and compare with this research for future extensions.

\section{ACKNOWLEDGMENT}

This work was supported in part by Ministry of Science and Technology, Taiwan, under Grant no. MOST 105-2221-E-274-002 and MOST 105-2815-C-274-003-U.

\section{REFERENCES}

[1] LearnMode, 2015.

[2] V. Viswanath, M. G. Morris, G. B. Davis, and F. D. Davis, "User acceptance of information technology: Toward a unified view," MIS Ouarterly, vol. 27, no. 3, pp. 425-478, 2003.

[3] J.-C. Tseng, "Effectiveness analysis of the use of CAI software Viewpoint and application of TAM," Educational Journal of National Hsinchu University of Education, vol. 26, no. 2, pp. 127-163, 2009.

[4] S.-H. Yang, "A study of tablet computers-assisted learning of English writing in high school," National Chiao Tung University Repository, 2013.
[5] R. L. Thompson, C. A. Higgins, and J. M. Howell, "Personal computing: Toward a conceptual model of utilization," MIS Quarterly, vol. 15 , no. 1 , pp. 125-143, 1991.

[6] F. D. Davis, R. P. Bagozzi, and P. R. Warshaw, "Extrinsic and Intrinsic Motivation to Use Computers in the Workplace," Journal of Applied Social Psychology, vol. 22, no. 14, pp. 1111-1132, 1992.

[7] I. Ajzen, "Attitudes, traits, and actions: Dispositional prediction of behavior in personality and social psychology," Advances in Experimental Social Psychology, New York: Academic Press, 1987.

[8] I. Ajzen and B. L. Driver, "Application of the theory of planned behavior to leisure choice," Journal of Leisure Research, vol. 24, no. 3, pp. 207-224, 1992.

[9] F. D. Davis et al., "User acceptance of computer technology: A comparison of two theoretical models," Management Science, vol. 35 , no. 8, pp. 982-1003, 1989

[10] M.-L. Wu, SPSS Manual and Applications - Practices of Statistical Analysis of Questionnaire Survey, Taipei, Taiwan: Wu-Nan Books Inc., 2010 .

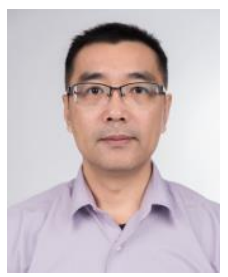

York M. Sun is currently a lecturer in the Department of Applied Digital Media at WuFeng University, Min-Hsiung, Chiayi County, Taiwan. He has over 10 years of teaching, research, and practice experience in the area of information systems. His current research interests include: e-learning, digital media design, and digital photography.

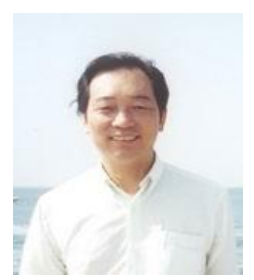

Rong Jou Yang received his bachelor of science in chemistry from National Kaohsiung Normal University, Taiwan in 1978 and the master of science in computer science from the University of Texas at El Paso in 1985 . He is currently a potential Ph.D. student in the Department of Computer Science at the University of Texas at El Paso, El Paso, Texas, USA

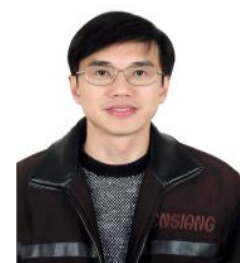

Hann-Jang Ho received his B.S. and M.S. degrees from National Taiwan University of Science and Technology in 1988 and 1990 respectively, and Ph.D. degree in computer science and information engineering from National Chung Cheng University, Taiwan in 2003. He is currently a professor in the Department of Applied Digital Media at WuFeng University, Min-Hsiung, Chiayi County, Taiwan.

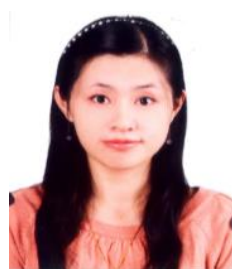

Yun-Ju Weng received her bachelor of accounting from Shih Chien University, Taiwan in 2001 and the master of applied digital media from Wu Feng University, Taiwan in 2016. She is currently a teacher in discipline of multimedia and leader of group of verification of technical ability at Private Dong $\mathrm{Wu}$ Senior Industrial Home Economics Vocational High School, Chiayi, Taiwan.

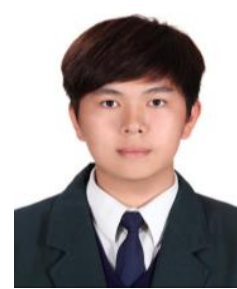

Bo-Zhang Chen is currently a student in the Department of Applied Digital Media and assists in the student research project funded by Minister of Science and Technology at WuFeng University, Min-Hsiung, Chiayi County, Taiwan. 